\title{
Constraints on effective pictorial and verbal elaboration
}

\author{
BARRY S. STEIN, KARLA F. BROCK, and DONNY R. BALLARD \\ Tennessee Technological University, Cookeville, Tennessee
}

and

\author{
NANCY J. VYE \\ University of Western Ontario, London, Ontario, Canada
}

\begin{abstract}
Three experiments investigated the conditions under which pictures facilitate learning. In Experiment 1, confusing verbal relationships were supplemented with pictures that illustrated the key concepts in each verbal relationship (base pictures), illustrated the key concepts in more elaborate arbitrary relationships (pictures of arbitrary elaborations), or illustrated the key concepts in ways that helped clarify the verbal relationships (pictures of explanatory elaborations). All three types of pictures facilitated the retention of the verbal relationships, although pictures of explanatory elaborations were superior to other types of visual illustrations. In Experiment 2, the facilitative effects of base pictures depended on a schematically unique illustration of the key concepts in a single image. In Experiment 3, picture facilitation effects were constrained by the type of verbal elaborations that accompanied the pictures. Specifically, base pictures and pictures of arbitrary elaborations did not facilitate the retention of confusing verbal relationships that were elaborated with explanatory information, and actually interfered with the retention of those explanatory elaborations. The implications of these results are discussed.
\end{abstract}

One strategy frequently used to help people understand new and confusing information is to represent that information in a visual illustration. Pictures or graphic illustrations are commonly used in lectures, films, textbooks, instruction manuals, computer software, and scientific articles to help people understand and learn new information. Despite the extensive use of visual illustrations, it remains unclear why pictures facilitate the comprehension and retention of verbal information and what factors influence the effectiveness of pictorial illustrations (e.g., Bluth, 1981; Brody, 1981; Levin, 1981; Samuels, 1970).

One way pictures could facilitate the comprehension and retention of information is by helping people relate new information to previous experience (elaboration). Substantial research suggests that comprehension and/or retention can be enhanced by providing additional elaborations during study (Anderson \& Reder, 1979; Craik \& Tulving, 1975; Fisher \& Craik, 1980; Rohwer, 1980; Stein \& Bransford, 1979; Stein, Littlefield, Bransford, \& Persam-

This research was supported in part by a faculty research grant to Barry Stein. Part of this research was presented at the Midwestern Psychological Association in Chicago, May 1985. We thank Kerry Way for helping us collect some of the data presented in this article and Rebecca Bowles for helping us prepare some of the illustrations. We also thank Douglas Nelson, Jim Dickinson, and Margaret Intons-Peterson for the helpful comments they provided on an earlier version of this manuscript.

Please address correspondence to: Barry S. Stein, Department of Psychology, Tennessee Technological University, Cookeville, TN 38505. pieri, 1984). Not all types of elaborative information, however, facilitate comprehension and retention. For example, Stein et al. (1984) tried to mimic the problem a novice faces when confronted with many confusing and arbitrary relationships in an unfamiliar domain. Their subjects were presented with a list of 10 base sentences (e.g., "The bald man used the telephone"; "The thin man picked up the scissors"; "The smart man used the charcoal"; "The short man bought the broom"). The base sentences were designed in such a way that the relationship between each type of man and the action performed seemed arbitrary.

Stein et al. (1984) found that elaborations that made the relationship between the attributes of the man and the activity performed in each base sentence less arbitrary (e.g., "The short man bought the broom to operate the light switch") significantly improved retention relative to the retention of subjects given only the base sentences. In contrast, elaborations that did not clarify why each man was performing the stated activity but simply provided more semantically congruous and nonredundant information (e.g., "The short man bought the broom to sweep the floor") did not facilitate retention. On the basis of these findings and other, similar results (Stein \& Bransford, 1979; Stein, Bransford, Franks, Owings, et al., 1982; Stein, Morris, \& Bransford, 1978), Stein and colleagues have argued that the effectiveness of verbal elaborations is influenced by the functional ability of the elaboration to reduce the apparent arbitrariness of confusing relationships for the learner. 
Although the research discussed above was conducted with verbal elaborations, similar constraints may influence the effectiveness of pictorial elaborations. That is, pictures may facilitate the comprehension and retention of verbal information when they prompt learners to activate the kind of knowledge that helps clarify relationships and make them less arbitrary or ambiguous. Within this theoretical approach, visual illustrations that do not prompt learners to activate knowledge needed to make relationships less arbitrary and ambiguous would not be expected to enhance the retention of verbal information (e.g., Bransford \& Johnson, 1972).

Alternatively, pictures and visual images may facilitate the comprehension and/or retention of verbal information because the visual image provides another way or an additional way of representing the verbal relationships. Both Nelson and Castano (1984) and Paivio (1971) have proposed that certain unique characteristics of visual representations underlie the facilitative effects of pictures. These approaches do not deal with the impact of pictorial elaboration on the clarification of relations depicted in visual illustrations.

The current study examines how the arbitrariness of relationships depicted in visual illustrations affects their value as an aid to learning verbal information. In Experiment 1 , subjects were presented with a list of base sentences similar to those used by Stein et al. (1984). Each base sentence described a certain type of man and his action without explaining the relation between the two. The sentences were presented alone or in combination with pictures illustrating those base sentences, pictures illustrating arbitrary elaborations of those base sentences, or pictures illustrating explanatory elaborations of those base sentences.

\section{EXPERIMENT 1}

\section{Method}

Subjects. Fifty-six undergraduates enrolled in introductory psychology courses at Tennessee Technological University participated for course credit.

Materials. Ten sentences describing the activities of 10 different men in relatively arbitrary relationships (e.g., "The short man bought the broom") were used as base sentences. These sentences, together with a set of explanatory elaborations for the base sentences (e.g., "The short man bought the broom to operate the light switch") and a set of arbitrary elaborations for the base sentences (e.g., "The short man bought the broom to sweep the floor"), were adapted from materials used by Stein et al. (1984). The sentences are presented in the Appendix. Three sets of pictures were constructued for these verbal statements, as shown in Figure 1. One set of pictures (base pictures) illustrated verbal information in the base sentences. A second set of 10 pictures (pictures of arbitrary elaborations) illustrated verbal information in the arbitrary elaborations of the base sentences. The third set of 10 pictures (pictures of explanatory elaborations) illustrated verbal information in the explanatory elaborations of the base sentences.

In order to verify that the explanatory elaborations were more effective aids for clarifying the key relationships in the base sentences than were the arbitrary elaborations, 15 subjects were presented with each of the 30 sentences listed in the Appendix and were asked to rate the degree to which each sentence explained the key relationship. The sentences were presented on a sheet of paper in a random order. Using a scale of 1 to 5 , with 5 meaning the sentence explained the key relationship very well, the subjects rated how well each statement explained why each type of man was performing the stated action. The mean ratings for the base sentences, arbitrary elaborations, and explanatory elaborations were 1.25, 2.34, and 4.65 , respectively. Analysis of variance showed differences to be statistically significant ${ }^{1}[F(2,28)=102, M S e=.443]$. Sentences with explanatory elaborations were rated significantly higher than sentences with arbitrary elaborations $[t(28)=9.51]$. Although sentences with arbitrary elaborations were also rated significantly higher than the base sentences $[t(28)=4.49]$, the difference in rat-

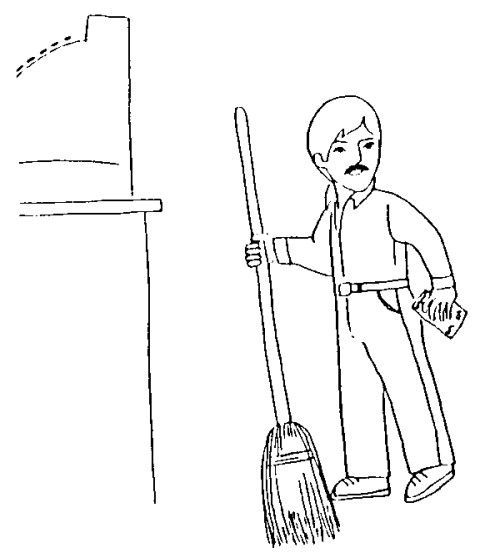

BASE

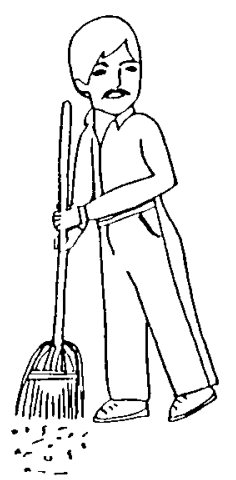

ARBITRARY

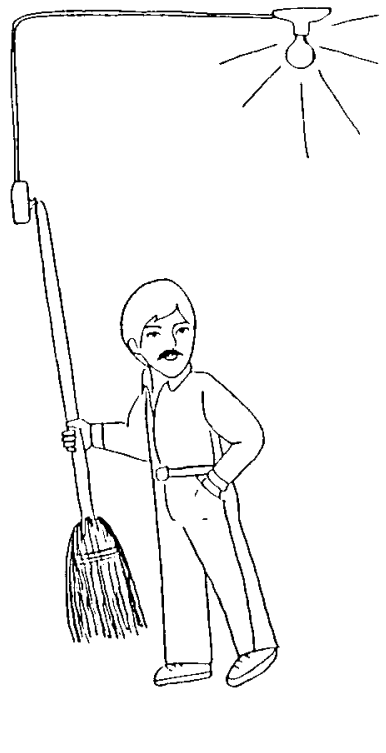

EXPLANATORY

Figure 1. Examples of pictures illustrating the base sentences, the arbitrary elaborations, and the explanatory elaborations. 
ings between the sentences with explanatory elaborations and the sentences with arbitrary elaborations was significantly greater than the difference in ratings between the sentences with arbitrary elaborations and the base sentences $[t(28)=3.55]$.

In order to verify that the pictures accurately depicted the verbal statements, 16 other subjects were presented with each of the $\mathbf{3 0}$ pictures (shown via slide projector) and were asked to describe what they saw. These subjects were shown each picture for $50 \mathrm{sec}$ and were instructed to select 1 of the 10 target adjectives printed on a sheet of paper and visible during all 30 trials as a subject in the picture (e.g., short, tall, etc.). No restrictions were placed on the number of times each adjective could be used. After an adjective had been selected, the subjects were instructed to use the chosen adjective in carefully describing the contents of each picture. The subjects' descriptions were analyzed in two ways. The descriptions were compared with the corresponding base sentences and were scored as correct if they contained both the appropriate target adjective (e.g., short) and the object of the action in the statement (e.g., broom). Descriptions such as "The short man bought the broom" and "The short man used the broom" were scored as correct. The mean numbers of correct descriptions of the base sentence relationships for the base pictures, pictures of arbitrary elaborations, and pictures of explanatory elaborations were 7.43, 7.12, and 7.75 , respectively. There were no significant differences among means.

An additional analysis was performed to determine how accurately the subjects could describe the elaborative relationships depicted in the arbitrary and explanatory pictures. The descriptions for explanatory pictures and arbitrary pictures were compared with the corresponding verbal statements and were scored as correct if the descriptions contained a paraphrase of the elaborative phrase. Two judges independently scored the sentences; the agreement between judges exceeded $87 \%$. The mean numbers of correct descriptions for the arbitrary and explanatory pictures were 7.12 and 7.56 , respectively. The difference between means was not statistically significant.

In order to verify that the pictures also differed in the extent to which they clarified the key base sentence relationship, a third group of 15 subjects viewed each of the pictures and rated how well each picture explained the key relationship in the base sentence. Each picture, together with the appropriate base sentence, appeared on a sheet of paper. Using a scale of 1 to 5 , with 5 meaning the picture explained the key relationship very well, the subjects rated how well each picture explained why each type of man was performing the action described in the base sentence. The mean ratings for the base picture, arbitrary picture, and explanatory picture were 1.64, 1.99 , and 4.24 , respectively. Analysis of variance showed these differences to be statistically significant $[F(2,28)=35.5, M S e=$ .84]. The explanatory pictures were rated significantly higher than the base pictures or the arbitrary pictures $[t(28)=7.76$ and $t(28)$ $=6.72$, respectively].

To determine whether subjects are aware of any systematic differences in the three picture sets that might influence the pictures' memorability, a fourth group of 15 subjects viewed each of the 30 pictures and rated how easy the information in the picture would be to remember. The subjects were instructed to use a scale of 1 to 5 , with 5 being easiest to remember. The order of the pictures was random. The mean ratings for the base pictures, pictures of explanatory elaborations, and pictures of arbitrary elaborations were $3.6,3.6$, and 3.48, respectively. The differences between means were not statistically significant

Design and Procedure. The subjects were assigned randomly to one of four experimental conditions (with equal numbers of subjects in each condition) in a completely randomized design and were tested in groups according to condition. The subjects in each condition were presented with the same 10 base sentences. The experimental conditions differed in the type of picture that was presented together with each verbal statement. The subjects received no pictures, base pictures, pictures of arbitrary elaborations, or pictures of explanatory elaborations. All subjects were given incidental learning instructions. The subjects in the no picture condition were instructed to rate the comprehensibility of each verbal statement on a scale of 1 to 5 , with 5 being the highest rating. The subjects in the three picture conditions were instructed to rate the degree to which each picture helped them understand the verbal statement on a scale of 1 to 5 , with 5 being the highest rating. Each verbal statement was presented orally. In each of the picture conditions, a slide projector displayed the picture of the corresponding statement at the beginning of the oral presentation. The subjects were given $7 \mathrm{sec}$ to rate each presentation. The pictures remained visible until the end of that 7 -sec period.

After acquisition, all subjects were asked to count backward by threes for $45 \mathrm{sec}$. The subjects were then read the 10 base sentence contexts (without the target adjective describing the type of man) as cues for the target adjective. After each cue had been presented orally, $5 \mathrm{sec}$ were allotted for each written response.

\section{Results}

The mean numbers of target adjectives recalled in the no picture, base picture, arbitrary picture, and explanatory picture conditions were $3.71,6.50,6.42$, and 8.57 , respectively. Analyses of variance performed on the number of items correctly recalled by each subject $[F(3,52)=$ $14.6, M S e=3.79]$ and on the number of subjects who correctly recalled the adjectives $[F(3,36)=10.7, M S \mathrm{e}$ $=7.24]$ showed these differences in recall to be statistically significant.

According to Dunn's multiple comparison procedure $\left(t^{\prime}\right)$, recall was reliably higher for the base picture and arbitrary picture conditions than for the no picture condition $\left[t^{\prime}(52)=3.79\right.$ and $t^{\prime}(52)=3.68$, respectively]. Furthermore, recall was reliably higher for the explanatory picture condition than for the base picture condition $\left[t^{\prime}(52)=2.8\right]$

\section{Discussion}

The results of Experiment 1 demonstrate that illustrations that do not provide information to help explain arbitrary and confusing verbal relationships can facilitate the retention of those verbal relationships. Specifically, significantly more target adjectives were recalled when the base sentences were presented together with illustrations of either the base sentences or the arbitrary elaborations than when the base sentences were presented alone. These results are consistent with the notion that there are certain aspects of the visual image that are represented differently in memory from the corresponding verbal code and that can enhance the retention of verbal information (Nelson \& Castano, 1984). Experiment 2 investigated the characteristics of the base pictures that contribute to the facilitation of base sentence retention.

The results of Experiment 1 also demonstrate that the recall of target adjectives in the base sentences was significantly higher when the base sentences were presented together with pictures of explanatory elaborations than when the base sentences were presented with pictures of the base sentences or pictures of arbitrary elaborations. 
One interpretation of these results is that the functional ability of a picture to clarify a confusing verbal relationship constrains the effectiveness of that picture as an aid to retention. However, whether these effects of pictures that clarify relationships are attributable to the verbal coding of explanatory information depicted in the illustration or to the visual representation of certain unique characteristics in the pictures of explanatory elaborations is unclear. Experiment 3 explored this issue.

\section{EXPERIMENT 2}

Experiment 2 examined the characteristics of the base pictures that contribute to the improved retention of base sentences by systematically manipulating different physical characteristics of the visual image. For example, one physical characteristic of the visual illustration that may influence the base picture effect is the degree of interaction between the man and the object (e.g., Begg \& Sikich, 1984; McKoon, 1981). The base pictures constructed for Experiment 1 frequently showed a high degree of interaction between the man and the object of his action (e.g., the short man holding a broom). To evaluate the importance of the man-object interaction in the base picture effect, Experiment 2 included a picture condition in which the man and object were illustrated without interaction (noninteracting base picture). Experiment 2 also included picture conditions that illustrated either only the man in each base picture (man-alone picture) or only the object in each base picture (object-alone picture). These latter conditions were included to evaluate the importance of illustrating the concepts involved in an arbitrary verbal relationship in a single picture (e.g., Begg \& Sikich, 1984).

Another factor that may have contributed to the base picture effect is the uniqueness of the visual illustration in each base picture. For instance, Nelson, Reed, and Walling (1976) found that the picture superiority effect was reduced or eliminated when the pictures they presented during acquisition were visually similar and difficult to discriminate from one another. Lesgold and Goldman (1973) also noted the importance of forming unique visual images in order to facilitate retention. To evaluate the importance of distinctive or unique visual information in the base picture effect, Experiment 2 included a picture condition in which less distinctive (i.e., schematically similar) men were illustrated in each base picture (nonunique base picture).

\section{Method}

Subjects. Eighty-four undergraduates enrolled in introductory psychology courses at Tennessee Technological University participated for course credit.

Materials. The 10 (base) verbal statements and 10 base pictures from Experiment 1 were used. In addition, four different variations of the base pictures were constructed. In the noninteracting base picture set, each base picture was reproduced with the man and object of the corresponding sentence separated and on opposite sides of the slide. In the man-alone picture set, the man depicted in each of the base sentence pictures was reproduced alone on a new slide without any additional information. In the object-alone picture set, the object of interaction (e.g., broom) in the base picture was reproduced alone on a new slide without any additional information. In the nonunique base picture set, each base picture was reproduced on a new slide with an image of a man that was relatively nonunique for each of the sentences. That is, each slide contained an image of a man that had features corresponding to at least four other men in the set (the same image could not be used for every sentence, since a man cannot be short and tall simultaneously or fat and thin simultaneously).

Design and Procedure. The subjects were assigned randomly to one of six different experimental conditions of equal size and were tested in groups. In one condition, the subjects received only the base sentences. In each of the other five conditions, the subjects were given the base sentences together with the corresponding pictures from the base picture, noninteracting base picture, nonunique base picture, man-alone picture, or object-alone picture set. The procedure was identical to that in Experiment 1, except that different pictures were used in some of the conditions.

\section{Results}

The mean numbers of target adjectives recalled in the no picture, base picture, noninteracting picture, nonunique picture, man-alone picture, and object-alone picture conditions were $3.78,6.57,6.07,5.00,3.50$, and 4.64 , respectively. Again, these differences were reliable according to analyses of variance performed on the number of items correctly recalled by each subject $[F(5,78)=5.15$, $M S e=4.04]$ and on the number of subjects who correctly recalled each item $[F(5,54)=2.78, M S e=10.2]$.

The subjects in the base picture condition recalled significantly more target words than did the subjects who received the base sentences alone $\left[t^{\prime}(78)=3.67\right]$, which replicated the base picture effect found in Experiment 1. The subjects in the noninteracting base picture condition also recalled significantly more target words than did the subjects who received the base sentences alone $\left[t^{\prime}(78)=\right.$ $3.01]$. In contrast, the subjects in the nonunique, manalone, and object-alone picture conditions did not recall significantly more target words than did the subjects in the no picture condition $\left[t^{\prime}(78)=1.60, t^{\prime}(78)=.37\right.$, and $t^{\prime}(78)=1.13$, respectively]. All comparisons used Dunn's multiple comparison procedure.

\section{Discussion}

The results of Experiment 2 replicate the base picture effect found in Experiment 1. The results also show that the visual interaction of the man and object within a shared picture is not a necessary condition for the base picture effect. The subjects who were given illustrations of noninteracting men and objects in the base sentences still remembered significantly more target words than did the subjects given no pictures. The discrepancy between these findings and other research suggesting the importance of interactive images (e.g., Begg \& Sikich, 1984) could be accounted for by the differences in materials used in the present experiment and other studies. In this experiment, the subjects were presented with meaningful sentence contexts that related the key concepts depicted in the pictures. The verbal statements may have provided adequate support for the integration of key concepts when accompanied by appropriate pictures. This explanation is consis- 
tent with other research that shows that meaningful relationships benefit about as much from interactive images as from other types of images (e.g., Begg, 1983).

The picture facilitation effect was disrupted when the illustrations depicted only either the man or the object alone in each base sentence. The subjects who were given either the man-alone picture or the object-alone picture did not remember significantly more target words than the subjects given no pictures. These results suggest that pictures designed to enhance the retention of arbitrary relationships must include both terms of the relationship in a single visual image. These findings are consistent with other research that has found picture facilitation effects for information included in the visual illustrations but not for verbal information that is not represented in visual illustrations (e.g., Levie \& Lentz, 1982).

The results of Experiment 2 also demonstrate that the graphic uniqueness of key concepts illustrated in a picture is an important determinant of the base picture effect. The subjects given relatively nonunique illustrations of men interacting with objects specified in the base sentences did not recall significantly more target concepts than the subjects given no pictures. In contrast, the subjects who were provided with relatively unique illustrations of men interacting with objects specified in the base sentences did recall significantly more target concepts than the subjects given no pictures. These results are consistent with other research demonstrating the superiority of relatively unique images to nonunique visual images (e.g., Lesgold \& Goldman, 1973; Nelson et al., 1976).

\section{EXPERIMENT 3}

The results of Experiment 1 indicate that illustrations of explanatory elaborations are more effective aids to retention than are illustrations of the base sentences or illustrations of arbitrary elaborations. The superior retention of the subjects given pictures of explanatory elaborations could have resulted from a combination of a base picture effect (i.e., a picture illustrating the key concepts involved in a verbal relationship) and an explanatory verbal elaboration effect (i.e., the subjects' verbally coding the explanatory relationship depicted in the picture).

Alternatively, the superior performance of the subjects given pictures of explanatory elaborations in Experiment 1 may have resulted from the unique representation of certain visual information in the pictures of explanatory elaborations. For instance, visual information that could help learners clarify the confusing base sentence relationships in the pictures of explanatory elaborations may influence the magnitude of the picture facilitation effects. In order to clarify why the pictures differentially affected retention, Experiment 3 examined the effects of base pictures, pictures of arbitrary elaborations, and pictures of explanatory elaborations on the retention of base sentences that were verbally elaborated with arbitrary or explanatory information. If the superior performance of the subjects given pictures of explanatory elaborations in Experi- ment 1 was attributable to the subjects' verbally coding the explanatory elaborations, then there should not be an explanatory picture effect (relative to the effect found for base pictures or pictures of arbitrary elaborations) for subjects given explanatory verbal elaborations. Alternatively, if the physical characteristics of the pictures of explanatory elaborations contribute to the superior performance, then subjects given pictures of explanatory elaborations should perform better than subjects given explanatory verbal elaborations together with base pictures or without pictures. Experiment 3 also included additional tests of retention to explore the effects that the three types of pictures have on the retention of the verbal elaborations presented with the base sentences.

\section{Method}

Subjects. One hundred and twelve undergraduates enrolled in introductory psychology courses at Tennessee Technological University participated for course credit.

Materials. The 10 base sentences together with 10 arbitrary elaborations and 10 explanatory elaborations from Experiment 1 were used as verbal stimuli. The three sets of base pictures, pictures of arbitrary elaborations, and pictures of explanatory elaborations from Experiment 1 were used as pictorial stimuli.

Design and Procedure. A 2 (explanatory vs. arbitrary verbal elaboration) $\times 4$ (no picture, base picture, arbitrary picture, explanatory picture) completely randomized factorial design was used. The subjects were assigned randomly to one of the eight experimental conditions, and were tested in groups. The subjects were distributed equally across the eight conditions and were given incidental learning instructions. The procedure was similar to that in Experiment 1 , except that half the subjects received explanatory verbal elaborations and the other half received arbitrary verbal elaborations during acquisition.

After acquisition, all subjects were asked to count backward by threes for $45 \mathrm{sec}$. The subjects were then read the 10 base sentence contexts (without the target adjective describing the type of man) as cues for the target adjective. After each cue had been presented orally, 5 sec were alloted for each written response.

After the cued-recall test for the target adjective had been administered, all subjects were given another recall test. The subjects were presented with each of the target adjectives orally and were asked to write down the complete sentence in which it occurred during acquisition. The subjects were given $50 \mathrm{sec}$ to respond to each target-adjective cue.

\section{Results}

Recall of target adjectives. Table 1 presents a summary of the mean number of target adjectives recalled in each condition. Analysis of variance performed on the number of items recalled by each subject showed significant effects for the type of verbal statement presented and the type of picture presented $[F(1,104)=10.4$ and $F(3,104)=7.56$, respectively, $M S \mathrm{Se}=3.97]$. Analysis

Table 1

Mean Number of Target Adjectives Recalled: Experiment 3

\begin{tabular}{lcccc}
\hline & \multicolumn{4}{c}{ Picture } \\
\cline { 2 - 5 } \multicolumn{1}{c}{ Verbal } & No Picture & Base & Arbitrary & Explanatory \\
\hline Arbitrary & 3.57 & 6.50 & 5.78 & 6.42 \\
Explanatory & 6.14 & 6.57 & 6.21 & 8.21 \\
\hline
\end{tabular}


of variance performed on the number of subjects who correctly recalled the adjectives also showed these effects to be reliable $[F(1,72)=7.67$ and $F(3,72)=5.57$, respectively, $M S e=7.53]$. Analysis of variance performed on the number of items correctly recalled by each subject showed that the interaction between type of verbal statement and type of picture presented approached significance $[F(3,104)=2.41]$.

Dunn's multiple comparison procedure $\left(t^{\prime}\right)$ was used to investigate these effects further. The subjects who received explanatory verbal elaborations together with either base pictures or pictures of arbitrary elaborations did not recall significantly more target adjectives than did the subjects who received explanatory verbal elaborations without pictures $\left[t^{\prime}(104)=.43\right.$ and $t^{\prime}(104)=.09$, respectively]. In contrast, the subjects who received explanatory verbal elaborations together with pictures of explanatory elaborations recalled significantly more target adjectives than did the subjects who received explanatory verbal elaborations without pictures $\left[t^{\prime}(104)=2.74\right]$.

In the arbitrary verbal elaboration conditions, the performance of subjects in each picture condition (base pictures, pictures of arbitrary elaborations, and pictures of explanatory elaborations) was significantly superior to the performance of subjects in the no picture condition $\left[t^{\prime}(104)=3.89, t^{\prime}(104)=2.93\right.$, and $t^{\prime}(104)=3.78$, respectively].

Recall of elaborations. Additional analyses were conducted to determine whether the pictures differentially affected the recall of verbal elaborations presented during acquisition. Two judges independently scored the subjects' responses on the second recall test for correct paraphrase of the entire elaborative statement that was orally presented in each condition. The agreement between judges exceeded $91 \%$. Table 2 presents the mean number of statements correctly recalled in each condition.

A two-way analysis of variance performed on the number of elaborations correctly recalled by each subject revealed statistically significant effects for the type of verbal statement presented and the type of picture presented $[F(1,104)=43.8$ and $F(3,104)=5.78$, respectively, $M S \mathrm{Se}$ $=6.39]$. These treatment effects were also reliable when a two-way analysis of variance was performed on the number of subjects who correctly recalled the elaborations $[F(1,72)=82.1$ and $F(3,72)=10.7$, respectively, $M S e$ $=4.61]$. Analysis of variance showed that the interaction between the type of verbal statement presented and the type of picture presented approached statistical significance for the number of elaborations correctly recalled by each subject $[F(3,104)=2.41]$ and reached sig-

Table 2

Mean Number of Elaborations Recalled: Experiment 3

\begin{tabular}{lcccc}
\hline & \multicolumn{4}{c}{ Picture } \\
\cline { 2 - 4 } Verbal & No Picture & Base & Arbitrary & Explanatory \\
\hline Arbitrary & 2.14 & 3.92 & 4.35 & 5.64 \\
Explanatory & 7.28 & 6.50 & 6.00 & 8.92 \\
\hline
\end{tabular}

Table 3

Percentage of Elaborations Recalled Given Target Adjective Recall: Experiment 3

\begin{tabular}{lcccc}
\hline & \multicolumn{4}{c}{ Picture } \\
\cline { 2 - 5 } \multicolumn{1}{c}{ Verbal } & No Picture & Base & Arbitrary & Explanatory \\
\hline Arbitrary & 30.9 & 55.1 & 62.3 & 67.5 \\
Explanatory & 92.0 & 71.4 & 75.6 & 93.8 \\
\hline
\end{tabular}

nificance for the number of subjects who recalled the elaborations $[F(3,72)=5.54]$.

Dunn's multiple comparison procedure $\left(t^{\prime}\right)$ was used to investigate these effects further. A comparison of performance in the four picture conditions revealed that subjects in the explanatory picture conditions (i.e., subjects who received either arbitrary or explanatory verbal elaborations) recalled significantly more elaborations than did the subjects in the other picture conditions (no pictures, base pictures, pictures of arbitrary elaborations) $\left[t^{\prime}(104)\right.$ $=4.08$ ].

Additional comparisons were performed to examine the effects of the pictures in the explanatory and the arbitrarily elaborated verbal conditions separately. The subjects who received explanatory verbal elaborations recalled significantly fewer elaborations when the base pictures or the pictures of arbitrary elaborations were presented than when no pictures or pictures of explanatory elaborations were presented $\left[t^{\prime}(104)=2.74\right]$. In the arbitrary verbal elaboration conditions, the subjects who received pictures of explanatory elaborations recalled significantly more arbitrary elaborations than did the subjects in the no picture condition $\left[t^{\prime}(104)=3.66\right]$. This latter finding was somewhat surprising and prompted a further inspection of the subjects' recall protocols in the explanatory picture/arbitrary verbal elaboration condition. This inspection revealed that the subjects tended to recall both the arbitrary verbal elaboration along with elements of the explanatory picture (differentiating the two sources of information in their protocols). Although the subjects given pictures of arbitrary elaborations (together with arbitrary verbal elaborations) tended to recall more elaborations than did the subjects given no pictures, this difference only approached significance $\left[t^{\prime}(104)=2.31\right]$.

Recall of elaborations given adjective recall. To investigate further the effects pictures have on the recall of elaborative information, the probability of recalling elaborative information given that the subjects had recalled the target adjective was calculated for each of the subjects. Table 3 presents the mean percentage of elaborations recalled given target-adjective recall for each condition.

A two-way analysis of variance on the conditional recall scores revealed statistically significant effects for the type of verbal statement presented, the type of picture presented, and the interaction $[F(1,104)=34.4, F(3,104)$ $=3.02$, and $F(3,104)=4.84$, respectively, $M S \mathrm{e}=696$ ]. In the explanatory verbal elaboration conditions, the subjects who received no pictures and pictures of explana- 
tory elaborations recalled a significantly higher percentage of elaborations given adjective recall than did the subjects who received base pictures or pictures of arbitrary elaborations $\left[t^{\prime}(104)=2.76\right]$. In the arbitrary verbal elaboration conditions, the subjects who received the pictures of arbitrary elaborations and pictures of explanatory elaborations recalled significantly higher percentages of elaborations given adjective recall than did the subjects who received no pictures $\left[t^{\prime}(104)=3.15\right.$ and $t^{\prime}(104)=$ 3.67 , respectively]. The difference in performance between the subjects who received the base pictures with arbitrary verbal elaborations and the subjects who received no pictures with arbitrary verbal elaborations approached significance $\left[t^{\prime}(104)=2.43\right]$. All comparisons were performed using Dunn's multiple comparison procedure.

One possible explanation for the effects obtained in Experiment 3 is that properties of the stimulus materials other than the arbitrariness of the elaborations contributed to the differences in retention. For example, the explanatory elaborations may have been more bizarre or humorous than the arbitrary elaborations, and these stimulus properties may have improved retention. To evaluate this hypothesis, ratings of bizarreness and humor were obtained from two different groups of subjects. The 10 arbitrary elaborations of the base sentences and the 10 explanatory elaborations of the base sentences were presented together on a sheet of paper in a random order to 15 subjects who were asked to rate the bizarreness of each sentence on a scale of 1 to 5 , with 5 being most bizarre. The mean ratings for the arbitrary and explanatory elaborations were 2.02 and 2.43 , respectively. The difference between means was not significant. The same set of sentences was also presented to another group of 15 subjects who were asked to rate how humorous each statement was on a scale of 1 to 5 , with 5 being most humorous. The mean ratings for the arbitrary and explanatory statements were 1.58 and 2.50 , respectively. The difference between means was reliable according to a $t$ test. To determine whether the humorous qualities of the explanatory elaborations affected retention, we examined the relationship between ratings of humor and the probability of correct recall for each explanatory sentence in the no picture condition. The mean probability of adjective recall for the five statements rated highest in humor was .50, and the mean probability of adjective recall for the five statements rated lowest in humor was .73. There was also a negative correlation between humor ratings and the probability of adjective recall for the subjects given the 10 explanatory elaborations without pictures $(r=-.53)$.

\section{Discussion}

The results of Experiment 3 suggest that the arbitrariness of relationships in both verbal and pictorial elaborations affects learning. The subjects who were given explanatory verbal elaborations that helped clarify arbitrary base sentence relationships generally recalled significantly more target adjectives and elaborations than did the sub- jects who were given arbitrary verbal elaborations that did not explain those confusing base sentence relationships. These results are consistent with previous research by Stein and Bransford (1979), Stein, Bransford, Franks, Vye, and Perfetto (1982), and Stein et al. (1984). The subjects given pictures illustrating information in the explanatory verbal elaborations also tended to have the highest levels of recall. The latter findings are consistent with the pattern of results obtained in Experiment 1.

The results of Experiment 3 also help to clarify why pictures that illustrate explanatory elaborations are more effective than pictures that illustrate the base sentences or arbitrary elaborations. In Experiment 1, the subjects who received illustrations of the explanatory verbal elaborations may have recalled more information than did the other subjects because they benefited from both a general picture facilitation effect (e.g., the base picture facilitation effect) and from the verbal recoding of the explanatory elaboration illustrated in the picture. To evaluate that hypothesis, Experiment 3 included conditions in which the subjects received explanatory verbal elaborations. Under these conditions, the subjects who received the pictures of explanatory elaborations still recalled significantly more target concepts than did the subjects in the no picture group even though explanatory verbal elaborations were also presented. In contrast, the subjects who received the base pictures or pictures of arbitrary elaborations did not recall more target concepts than did the subjects who received the explanatory verbal elaborations without pictures. These findings suggest that the information illustrated in the pictures of explanatory elaborations is represented differently in memory from the verbal statements those pictures were designed to illustrate.

The findings of Experiment 3 also clarify some of the situations in which pictures do not facilitate the retention of verbal information. Although picture facilitation effects were observed for each type of picture in Experiment 1, the results of Experiment 3 suggest that picture facilitation effects are constrained by the type of verbal elaboration that is being learned. For example, when subjects were given explanatory verbal elaborations that clarified the arbitrary base sentence relationships, the presentation of base pictures or pictures of arbitrary elaborations did not facilitate retention. It should be noted that both the base pictures and the pictures of arbitrary elaborations illustrated the key elements of each verbal relationship (e.g., a short man/broom) in a shared visual image (a constraint on picture facilitation effects identified in Experiment 2). These findings suggest that certain picture facilitation effects may be attenuated in situations in which the learner has activated appropriate knowledge to clarify potentially confusing relationships.

One alternative explanation for the picture facilitation effects observed in Experiment 3 is that the facilitative effects of pictures depend on the degree to which the meaning of the picture and the verbal statement coincide. The correspondence hypothesis is consistent with the observation that the retention of target concepts in base sen- 
tences elaborated with explanatory statements was facilitated only by pictures of explanatory elaborations. Certain findings in the present study, however, question the adequacy of such an explanation. For example, in Experiment 1 , the subjects who received the base sentences together with the pictures of explanatory elaborations recalled significantly more target concepts than did the subjects who received the base sentences together with the pictures of the base sentences. Furthermore, in Experiment 3 , the subjects who received the pictures of explanatory elaborations together with arbitrary verbal elaborations recalled as much information or more information than did the subjects who received pictures of arbitrary elaborations together with arbitrary verbal elaborations. The similarity in meaning or content between the pictures and verbal statements does not account for the picture facilitation effects observed in these latter situations. Instead, the results suggest that picture facilitation effects may be influenced more directly by the extent to which the pictures illustrate information that clarifies or explains arbitrary relationships.

Although the base pictures and the pictures of arbitrary elaborations did not appear to influence the recall of target adjectives in the conditions that received explanatory verbal elaborations, those pictures did affect elaboration recall. Specifically, the subjects who received the explanatory verbal statements together with the base pictures or the pictures of arbitrary elaborations recalled significantly fewer explanatory elaborations than did the subjects who received no pictures or pictures of explanatory elaborations. These results indicate that pictures that do not help to explain arbitrary relationships can actually interfere with the retention of explanatory verbal elaborations that could facilitate comprehension. These findings may help explain why other studies have failed to demonstrate facilitative effects of pictures on comprehension (e.g., Reid, Briggs, \& Beveridge, 1983). Although other research (e.g., Peeck, 1974) has indicated that pictures can adversely affect learning if they contain information contradictory to a text, the present findings suggest that such interference effects can occur even when the pictures do not contradict any of the information presented verbally.

In the arbitrary verbal elaboration conditions, the subjects appeared to benefit from the presentation of base pictures, pictures of arbitrary elaborations, or pictures of explanatory elaborations. Each of the three picture conditions significantly improved the recall of target adjectives over that in the no picture group. Unlike the pattern of results found in Experiment 1, the pictures of explanatory elaborations did not produce significantly higher levels of adjective recall than did the other picture conditions. The smaller effect observed for explanatory pictures in these Experiment 3 conditions may have been caused by interference from the confusing arbitrary verbal elaborations presented during study. However, despite the lack of correspondence between picture and verbal elaboration, only the pictures of explanatory elaborations, and to a lesser extent the pictures of arbitrary elaborations, reliably improved the retention of the arbitrary verbal elaborations over that in the no picture condition. The facilitative effects observed for the pictures of arbitrary elaborations on elaboration recall might be accounted for by the representation of the elaborative information in the visual image. However, an explanation of why pictures of explanatory elaborations facilitated the recall of arbitrary verbal elaborations is less clear. One possible explanation for the latter effect is that pictures that help clarify confusing relationships can facilitate the integration of verbal information that is not depicted in the pictures.

The analysis of conditional recall (the probability of recalling the elaboration given adjective recall) reported in Experiment 3 suggests that explanatory and arbitrary elaborations differ in the extent to which they help integrate the information presented in a verbal statement. For example, the subjects given explanatory verbal elaborations generally tended to have higher probabilities of recalling the elaboration given adjective recall than did the subjects given arbitrary verbal elaborations. This difference in conditional recall was most dramatic in the no picture conditions in which differences in adjective retention were most pronounced. However, it is surprising that differences in conditional recall persist even when arbitrary and explanatory verbal elaboration conditions that had roughly equivalent levels of adjective recall are compared (e.g., explanatory verbal elaborations/no pictures vs. arbitrary verbal elaboration/pictures of arbitrary elaborations). These findings suggest that elaborative information can differentially affect the retention of concepts and relationships within a sentence and that explanatory elaborations facilitate the integration of verbal information more than do arbitrary elaborations.

\section{GENERAL DISCUSSION}

The pattern of results obtained in the present study suggests that the precise effect any picture has on learning verbal information will be a function of several interacting factors. One factor that constrains picture facilitation effects is the way in which verbal information is illustrated pictorially. For example, visual illustrations enhanced the retention of arbitrary and confusing verbal relationships in Experiment 2 when the pictures uniquely illustrated the key concepts involved in each relationship in a single visual image. Pictures that illustrated only one of the concepts involved in a relationship or illustrated concepts using relatively nonunique schematic drawings were less effective aids to retention.

Another factor that appears to influence the magnitude of picture facilitation effects is the type of elaborative information that is illustrated in the picture. For example, pictures that illustrated information that could help learners to clarify the arbitrary verbal relationships presented in Experiment 1 facilitate retention more than 
did pictures that did not illustrate elaborative information that could clarify the confusing base sentence relationships.

The precise effects that pictures have on the retention of verbal information also appears to be constrained by the type of verbal relationship being learned. For example, pictures that uniquely illustrated the key concepts involved in confusing verbal relationships (base pictures) facilitated the retention of the base sentence relationships in Experiments 1 and 2. However, when the confusing base sentence relationships were elaborated with explanatory verbal information (in Experiment 3), the presentation of base pictures did not facilitate the retention of base sentence relationships. These findings suggest that picture facilitation effects can be attenuated when learners are able to clarify potentially confusing verbal relationships with other kinds of verbal information. In the current study, the experimenter provided the explanatory verbal elaborations. In other learning contexts, however, explanatory verbal elaborations could be generated by learners themselves (e.g., Stein, Bransford, Franks, Owings, et al., 1982). These self-generated elaborations could also constrain picture facilitation effects.

Each of the constraints on picture facilitation effects discussed above could help explain why picture facilitation effects vary in magnitude and consistency from one study to another (e.g., Levie \& Lentz, 1982; Readence \& Moore, 1981). The current findings suggest that a precise evaluation of the benefits of any particular picture requires a more complete analysis of the learning context. This conclusion is consistent with the contextualist approach outlined by Jenkins $(1974,1979)$.

The picture facilitation effects reported in the present study are consistent with the idea that certain aspects of the visual image may be represented differently in memory than verbal information (e.g., Nelson \& Castano, 1984; Paivio, 1971). The present findings suggest that this alternate representation can be used in certain situations to improve the retention of verbal information. For example, pictures illustrating information in the base sentences facilitated the retention of base sentence information. The results of this study, however, also suggest that the facilitative effects of pictorial and verbal elaborations are not always additive. For example, illustrations of the base sentences did not facilitate retention when subjects were given explanatory verbal elaborations that helped clarify the arbitrary relationships. Furthermore, the present findings suggest that there are some similarities in the constraints that govern the facilitative effects of verbal and pictorial elaborations on retention. For instance, the effectiveness of both verbal and pictorial elaborations appears to be influenced by the extent to which the information provided in the elaboration clarifies or explains confusing relationships.

The findings discussed above also have implications for the use of pictorial illustration and visual imagery as an aid to the comprehension and retention of verbal infor- mation. The results indicate that depending on the nature of the visual image and the nature of the verbal information presented, visual illustrations presented or imagined during the encoding of verbal information can either facilitate or debilitate comprehension and learning. For example, a visual image that represents simply the key concepts in a confusing verbal relationship may help learners to remember that relationship. Such pictures may have little effect on retention, however, if verbal information that helps to clarify the relationship and make it less arbitrary is provided (e.g., is generated by the learner or supplied elsewhere in the text). Furthermore, visual images that simply represent key concepts involved in arbitrary verbal relationships may interfere with the retention of information that could otherwise help learners explain relationships and make those relationships less arbitrary. In contrast, visual images that illustrate information needed to help learners clarify confusing relationships have more consistent and positive effects on comprehension and retention.

\section{REFERENCES}

Anderson, J. R., \& ReDER, L. M. (1979). An elaborative processing explanation of depth of processing. In L. S. Cermak \& F. I. M. Craik (Eds.), Levels of processing and human memory. Hillsdale, $\mathrm{NJ}$ : Erlbaum.

BEGG, I. (1983). Imagery instructions and the organization of memory. In J. C. Yuille (Ed.), Imagery, memory and cognition. Hillsdale, $\mathrm{NJ}$ : Erlbaum.

BEGG, I., \& SiKICH, D. (1984). Imagery and contextual organization. Memory \& Cognition, 12, 52-59.

BLuTh, L. F. (1981). The illustration-comprehension relationship: A review of the literature. Reading Improvement, 18, 251-258.

Bransford, J. D., \& Johnson, M. K. (1972). Contextual prerequisites for understanding: Some investigations of comprehension and recall. Journal of Verbal Learning \& Verbal Behavior, 11, 717-726.

BRoDY, P. J. (1981). Research on pictures in instructional texts: The need for a broadened perspective. Educational Communication \& Technology Journal, 29, 93-100.

Craik, F. I. M., \& TUlviNG, E. (1975). Depth of processing and the retention of words in episodic memory. Journal of Experimental Psychology: General, 104, 269-294.

Fisher, R. P., \& Craik, F. I. M. (1980). The effects of elaboration on recognition memory. Memory \& Cognition, 8, 400-404.

JENKINS, J. J. (1974). Remember that old theory of memory? Well, forget it! American Psychologist, 29, 785-795.

JeNkINS, J. J. (1979). Four points to remember: A tetrahedral model of memory experiments. In L. S. Cermak \& F. I. M. Craik (Eds.), Levels of processing and human memory. Hillsdale, NJ: Erlbaum.

LESGOLD, A. M., \& GoldmaN, S. R. (1973). Encoding uniqueness and the imagery mnemonic in associative learning. Journal of Verbal Learning \& Verbal Behavior, 12, 193-202.

LEVIE, W. H., \& LENTZ, R. (1982). Effects of text illustrations: A review of research. Educational Communication \& Technology Journal, 30 , 195-232.

LEvin, J. R. (1981). On functions of pictures in prose. In F. J. Pirozzolo \& M. C. Wittrock (Eds.), Neuropsychological and cognitive processes in reading. New York: Academic Press.

McKoon, G. (1981). Notes, comments, and new findings: The representation of pictures in memory. Journal of Experimental Psychology: Human Learning \& Memory, 7, 216-221.

Nelson, D. L., \& CaSTANo, D. (1984). Mental representations for pictures and words: Same or different? American Journal of Psychology, 97, 1-16. 
Nelson, D. L., Reed, V. S., \& Walling, J. R. (1976). Pictorial superiority effect. Joumal of Experimental Psychology: Human Learning \& Memory, 2, 523-528.

PaIvio, A. (1971). Imagery and verbal processes. New York: Holt, Rinehart \& Winston.

PEECK, J. (1974). Retention of pictorial and verbal content of a text with illustrations. Journal of Educational Psychology, 66, 880-888.

Readence, J. E., \& Moore, D. W. (1981). A meta-analytic review of the effect of adjunct pictures on reading comprehension. Psychology in the Schools, 18, 218-224.

ReID, D. J., Briggs, N., Beveridge, M. (1983). The effect of picture upon the readability of a school science topic. British Journal of Psychology, 53, 327-335.

ROHWER, W. D., JR. (1980). An elaborative conception of learner differences. In R. E. Snow, P. A. Frederico, \& W. E. Montague (Eds.), Apititude, learning, and instruction. Hillsdale, NJ: Erlbaum.

SAmuELS, S. J. (1970). Effects of pictures on learning to read, comprehension and attitudes. Review of Educational Research, 40, $397-407$

Stein, B. S., \& Bransford, J. D. (1979). Constraints on effective elaboration: Effects of precision and subject generation. Journal of Verbal Learning \& Verbal Behavior, 18, 769-777.

Stein, B. S., Bransford, J. D., Franks, J. J., Owings, R. A., Vye, N. J., \& MCGRAW, W. (1982). Differences in the precision of selfgenerated elaborations. Joumal of Experimental Psychology: General, 111, 399-405.

Stein, B. S., Bransford, J. D., Franks, J. J., Vye, N. J., \& PerFETTO, G. A. (1982). Differences in judgments of learning difficulty. Journal of Experimental Psychology: General, 111, 406-413.

Stein, B. S., LitTlefield, J., Bransford, J. D., \& Persampieri, M. (1984). Elaboration and knowledge acquisition. Memory \& Cognition, 12, 522-529.

Stein, B. S., Morris, C. D., \& Bransford, J. D. (1978). Constraints on effective elaboration. Joumal of Verbal Learning \& Verbal Behavior, 17, 704-714.

\section{NOTE}

1. An alpha level equal to .05 was adopted for all statistical procedures.

\section{APPENDIX}

Verbal Statements

Base Sentences

1. The short man bought the broom.

2. The old man used the paint.

3. The fat man looked at the warning.

4. The funny man bought a ring.

5. The smart man used the charcoal.

6. The big-footed man bought some signs.

7. The strong man talked to the woman.

8. The thin man picked up the scissors.

9. The bald man used the telephone.

10. The tall man bought the crackers.

Base Sentences and Arbitrary Elaborations

1. The short man bought the broom to sweep the floor.

2. The old man used the paint to cover the spot on the wall.

3. The fat man looked at the warning that said keep off the grass.

4. The funny man bought a ring afier the pencil broke.

5. The smart man used the charcoal that was on the top shelf.

6. The big-footed man bought some signs that warned about thin ice.

7. The strong man talked to the woman about the light switch.

8. The thin man picked up the scissors to cut the tag off his hat.

9. The bald man used the telephone to call the moving company.

10. The tall man bought the crackers that were on sale.

Base Sentences and Explanatory Elaborations

1. The short man bought the broom to operate the light switch.

2. The old man used the paint to change the color of his cane.

3. The fat man looked at the warning that said keep off the thin ice.

4. The funny man bought a ring that squirted water.

5. The smart man used the charcoal to write the message when the pen broke.

6. The big-footed man bought some signs that said keep off my feet.

7. The strong man talked to the woman about moving her television set.

8. The thin man picked up the scissors to cut the belt in half.

9. The bald man used the telephone to call about the hat sale.

10. The tall man bought the crackers that were on the top shelf.

(Manuscript received March 13, 1986;

revision accepted for publication November 6,1986 .) 